\title{
O DESIGN E A VALORIZAÇÃO DO VERNACULAR OU DE PRÁTICAS REALIZADAS POR NÃO-DESIGNERS.
}

\author{
Ibarra, Maria Cristina.; MSc; \\ Universidade do Estado de Minas Gerais \\ mariacih@gmail.com \\ Ribeiro A.C., Rita.; Dra; \\ Universidade do Estado de Minas Gerais \\ rribeiroed@gmail.com
}

\begin{abstract}
Resumo: O objetivo deste artigo é contribuir na formação de um referencial teórico relacionado com o design e a valorização do vernacular ou de práticas realizadas por não-designers. Inicialmente apresenta-se a relação da arquitetura com o vernacular tomando em conta que foi nesta área que grande parte dos primeiros estudos foi realizada. Posteriormente, mostra-se a relação do design com este tipo de manifestações em países europeus e norteamericanos. E finalmente apresenta-se essa valorização no Brasil. $O$ resultado obtido é a disponibilização de vários casos de pesquisa e divulgação de práticas feitas por não-designers, tema que o design vem se aproximando cada vez mais nos últimos anos.
\end{abstract}

Palavras-chave: Design Vernacular, arquitetura vernacular, práticas realizadas por não-designers.

\begin{abstract}
The purpose of this article is to contribute to the formation of a theoretical framework related to the design and enhancement of the vernacular or practices carried out by non-designers. Initially we present the relation of the architecture with the vernacular taking into account that was in this area where a big part of the first studies was performed. Then, we show the relation of design with this kind of manifestations in Europe and North America. And finally we present this valorization here in Brazil. The obtained result is the availability of several cases of research and dissemination of practices made by non-designers, topic that design comes approaching increasingly in recent years.
\end{abstract}

Keywords: Design Vernacular. Arquitetura vernacular. Practices carried out by non-designers. 


\section{INTRODUÇÃO}

No design, em termos gerais, pode-se ver nos últimos anos um ressurgimento do interesse pelas manifestações vernaculares, pelos objetos que nascem na rua, que são utilizados como meio de vida, feitos por vendedores ambulantes, por moradores de rua, ou por qualquer outra pessoa a partir da espontaneidade. Estes artefatos ${ }^{1}$ têm sido (e estão sendo) estudados como expressões de uma região e da sua cultura material, desde sua produção através do reuso de elementos que contribuem à sustentabilidade, como a carência e a falta de recursos incentivam a criatividade e a invenção, como os novos usos que os usuários dão aos artefatos industriais se transformam em design, e em geral, qual tem sido sua contribuição ao design como disciplina. (FIG.1)

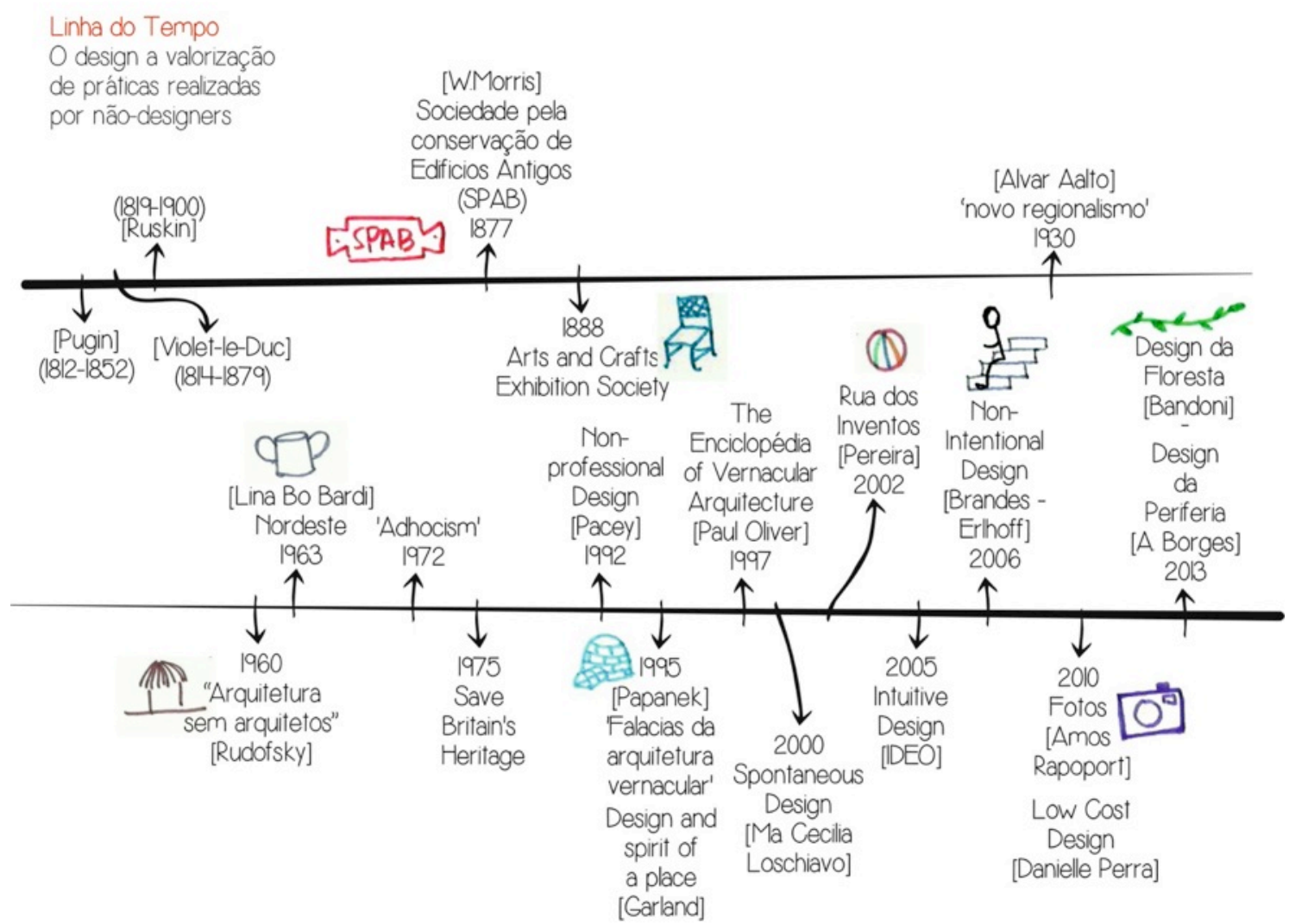

Figura 1 - Linha do tempo. Fonte: Elaborado pela autora com base na pesquisa realizada

No seguinte artigo mostraremos como e desde quando vem acontecendo esta aproximação começando pela arquitetura vernacular, já que conforme Priscila Farias

${ }^{1}$ O termo "artefato" é empregado com a seguinte acepção: "Forma individual de cultura material ou produto deliberado da mão-de-obra humana" HOUAISS, A. Dicionário Houaiss da Língua Portuguesa. Rio de Janeiro. Ed. Objetiva. 2001 
(2011), foi no campo da arquitetura que grande parte dos primeiros estudos sobre o design vernacular, ou o design praticado por não-designers, foi realizada.

\section{RELAÇÃO DA ARQUITETURA COM O VERNACULAR}

Segundo o dicionário Houaiss (2007), o termo vernacular é um adjetivo que qualifica algo como próprio de uma nação, região ou país, também se diz de uma linguagem sem estrangeirismos na pronúncia, vocabulário ou construções sintáticas, castiço. Segundo o filólogo Chester Star Jr (1942), o termo 'vernáculo' tem origem na expressão latina verna ou vernaculus que originalmente foi usada para designar algo nativo, um nativo da cidade de Roma ou mais especificamente, um escravo nascido em casa romana (STAR, 1942 apud FARIAS, 2011). Darron Dean (1994) escreve que o termo vernacular se deriva da palavra latina 'vernáculas' que significa nativo ou indígena, e que foi associada ao design pela primeira vez por George Gilbert Scott em 1857 e desde esse momento tem se desenvolvido uma grande literatura a seu respeito. (DEAN, 1994, p.153)

Segundo Kingston Wm. Heath (2003), na literatura, vernacular se refere à linguagem usada, reconhecida e compreendida por uma região específica, em contraste à linguagem formal de uma elite que tem um nível diferente de cultura. $A$ arquitetura vernacular, como o autor usa o termo, está composta por formas comuns e cotidianas que são familiares para certa população e que são geradas com materiais disponíveis geralmente com uma aplicação funcional. Para ele, o vernacular é produzido por um indivíduo para seu próprio uso, ou por construtores anônimos e locais que respondem a fórmulas localmente adaptadas.

No seu livro Vanguardia y Tradición, Vicky Richardson (2001), diretora de arquitetura, design e moda do British Council, faz uma recapitulação sobre a inclinação dos arquitetos ao vernacular. A autora utiliza o termo vernacular como um atalho para se referir a obras que adotam o espírito do vernáculo, mas não suas formas reais. Ela assinala que durante o século $\mathrm{XX}$, o interesse pelos edifícios como manufatura artesã não desapareceu absolutamente e que nos últimos anos tem tido um ressurgimento do vernáculo que lembra o movimento inglês Arts \& Crafts.

O nome do movimento Arts and Crafts foi cunhado devido à exposição Arts and Crafts Exhibition Society realizada em Novembro de 1888 na New Gallery em Londres, que considerava que "o declive da arte e do design se devia a uma ênfase excessiva na aprendizagem acadêmica, à separação entre design e produção, e se originava por artesãos ou artistas impessoais que produziam sua obra para um público impessoal". (RICHARDSON, pág. 7, 2001, tradução nossa) ${ }^{2}$ Os arquitetos envolvidos neste movimento, segundo a autora, não seguiam uma única linha, senão que

\footnotetext{
${ }^{2}$ Consideraba que el declive del arte y del diseño era resultado de un énfasis excesivo en el aprendizaje académico, de la separación entre diseño y producción, y se originaba por artesanos y artistas impersonales que producían su obra para un público impersonal.
} 
pegavam diferentes aspectos do vernáculo, como por exemplo, o uso de materiais locais, de estruturas materiais simples, o trabalho com harmonia com a paisagem, etc., e nunca se referiram a suas obras como resultado da valorização do vernáculo, senão que falavam de "sistemas locais". Suas obras eram um reflexo do medo de que a tradição local desaparecesse por causa da estandardização e colocavam seus esforços na documentação de edifícios rurais como pousadas, granjas, e construções tradicionais campesinas.

Prévio ao movimento Arts and Crafts, em 1877, William Morris, que depois foi um dos principais exponentes do movimento, criou a Sociedade pela Conservação de Edifícios Antigos (SPAB por suas siglas em inglês), que defendeu os edifícios campesinos do mesmo modo que as catedrais e as igrejas. A sociedade converteu-se numa escola de construção de edifício tradicionais.

Um predecessor das ideias de Morris foi Pugin (1812-1852), que em 1840 promulgava o gótico como um estilo próprio da Inglaterra e chamava o renascimento de técnicas construtivas tradicionais como a incorporação da forja, as vidreiras, e a cerâmica. John Ruskin (1819-1900), o crítico de arquitetura inglês, também concordava com a adoção do gótico e do vernáculo, pois acreditava que a arquitetura clássica era produzida por homens-máquina, pelas suas linhas precisas e leis definidas, dando-lhe um valor humano à imperfeição do trabalho artesanal.

Na Europa Continental, o arquiteto francês Violet-le-Duc defendia um retorno às tradições construtivas regionais, com a criação de um movimento antiinternacional, que influenciou as ideias de importantes arquitetos como o espanhol Antônio Gaudí (1852-1926), o belga Victor Horta (1861-1947), ou o holandês Hendrik Petrus Berlage, que promoveram formas de arquitetura nacional.

Em 1930, a obra de Alvar Aalto, considerada como o "novo regionalismo", mostrava que a arquitetura pode adotar o espírito do vernáculo sem recorrer ao mimetismo das suas formas. Richardson (2001) assinala que os edifícios de Alto se caracterizavam não só pela inspiração nos contornos curvos dos lagos finlandeses e pela utilização de materiais locais, mas também pela estandardização e a sensibilidade moderna internacional.

Nos anos 60, no Metropolitan Museum of Art de Nova lorque, especificamente no ano de 1964, se apresentou a exposição "Arquitetura sem arquitetos" a cargo do antropólogo Bernhard Rudofsky, onde pela primeira vez os habitáculos construídos por seus próprios moradores, especialmente os do terceiro mundo, foram mostrados como "obras de arquitetura" belas e funcionais (RUDOFSKY, 1964). Victor Papanek (1995) no livro Arquitetura e Design. Ecologia e ética observa que:

Desde meados do século XX que arquitetos, antropólogos e historiadores de arte se mostram cada vez mais interessados na arquitetura vernácula, tanto nos ambientes urbanos como nos rurais. Muitos edifícios, tipos de construções e urbanizações, nunca antes estudados a sério, têm sido documentados através de fotografias e descrições escritas. Esta tendência recebeu forte apoio como a exposição "Arquitetura sem Arquitetos", organizada por Bernard Rudofsky no Museu de Arte de Moderna, em Nova lorque, em 1963, 
bem como nos seus dois livros subsequentes. (PAPANEK, 1995, Pág. 127)

Nos anos 70 na Grã-Bretanha, houve uma mudança de atitude que deslocou a construção de novas edificações favorecendo a reabilitação de edificações antigas. Em 1975, iniciou-se um movimento conservacionista com a criação do Save Britain's Heritage (Salve a Herança Britânica) para proteger as antigas casas inglesas, e em 1979 se traduz para o inglês o livro do arquiteto alemão e crítico do Art Noveau, Hermann Muthesius, Das Englische Haus, que havia transportado as ideias do Art \& Crafts ao norte de Europa. (RICHARDSON, 2001)

Muito depois, em 1995, Victor Papanek assinala que a história da arquitetura está bem documentada através de edificações das classes mais altas como palácios, castelos, catedrais e casas de comerciantes, e que muitas delas ainda sobrevivem, outras já foram reconstruídas, de outras se conservam seus planos e desenhos, no entanto, das moradas mais modestas é difícil de achar registros. Também para abordar de maneira mais profunda, o tema expõe seis falácias acerca da arquitetura vernacular: A falácia histórica, a exótica, a romântica, a falácia da cultura popular, da tradição atual, e a sagrada.

-Falácia histórica: Muitas edificações não servem como exemplos vernáculos apenas em função de sua idade, mas porque constituem padrões de construção tradicional.

-Falácia exótica: As construções como os iglus dos esquimós ou as aldeias dos Batak na ilha de Sumatra na Indonésia, podem ter atribuída a elas uma importância ilusória em relação ao vernacular devido a seu caráter exótico.

-Falácia romântica: Na escrita sobre o vernáculo, é difícil encontrar uma discussão inteligente sobre estruturas de aldeias ou esquemas primitivos, pois os sistemas de construção exóticos que foram transportados para a arquitetura requintada são evitados pelos críticos romântico-sentimentais.

-Falácia da cultura popular: Não é qualquer estrutura que seja repetida com poucas variações, que pode ser chamada de vernácula. As redes de fastfood como Mc Donalds ou Wendy, não podem ser chamadas de estruturas vernaculares americanas dos finais do século XX. Elas são estruturas que identificam marcas de fábrica e a razão de sua existência é a venda, bem diferente das verdadeiras construções vernáculas ou nativas.

-Falácia da tradição atual: Não se pode dizer que as construções com características parecidas onde mora uma grande quantidade de pessoas numa região constitui uma expressão do vernáculo, pois estas habitações podem ser resultado de uma produção centralizada e processos de design.

-Falácia Sagrada: Existem aspectos vernáculos nos edifícios arraigados nas crenças religiosas de um povo, mas esses aspectos podem ser acrescentados pelo seu sentido sagrado e não pela sua representação de processos vernáculos.

Finalmente, o autor também aborda o tema a partir dos processos, assinalando que a arquitetura vernacular está baseada em conhecimentos sobre práticas e técnicas tradicionais, é usualmente autoconstruída, e respeita a qualidade e as habilidades. (PAPANEK, 1995) 
Em 1997, foi lançada The Enciclopedia of Vernacular Arquitecture, o primeiro estudo internacional sobre edifícios vernáculos, editada por Paul Oliver que incluía a obra de 250 investigadores de 80 países, cujo objetivo era a sobrevivência dos edifícios nativos indígenas frente à inexorável modernização (RICHARDSON, 2001).

Em maio de 2010, a Escola de Arquitetura, Design e Planejamento, da Universidade de Kansas, nos Estados Unidos, tornou pública a coleção de imagens de Arquitetura Vernacular de Amos Rapoport, que é a maior coleção de imagens digitais, publicamente acessível focada em Design Vernacular no mundo. A coleção abrange mais de 30.000 imagens tiradas pelo professor Rapoport em mais de 70 países, e representa mais de meio século de viagens a muitas partes do mundo, desde grandes cidades, até pequenas vilas (FIG. 2).

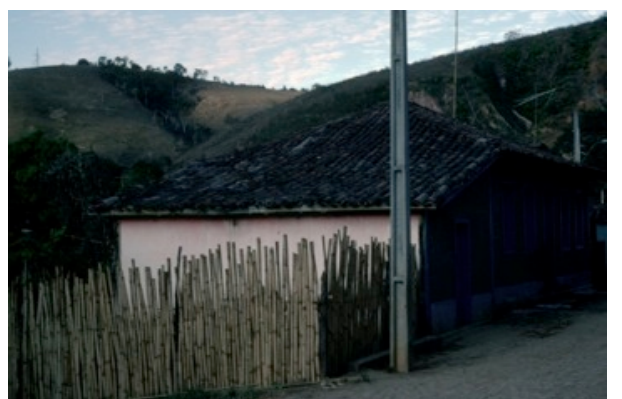

Figura 2 - Arquitetura Vernacular - Minas Gerais (Image Collection of Vernacular Design). Fonte: RAPOPORT, 2010

\section{RELAÇÃO DO DESIGN COM O VERNACULAR}

O design como disciplina começou a se interessar pelos artefatos feitos por não-designers, relativamente há pouco tempo. Em 1972, Charles Jencks e Nathan Silver propuseram o conceito "Adhocism", que faz referência à improvisação através do uso de objeto aleatórios com o objetivo de satisfazer uma necessidade momentânea. (BRANDES; STICH; WENDER, 2009)

Em 1992, Philp Pacey, escreveu o artigo Anyone designing Anything? NonProfessional Designers and the History of Design, em que mostra diferentes casos de design feitos por não profissionais.

Ken Garland (2004), na sua palestra oferecida em 1995 na Escola de Arte da Universidade de Michigan, titulada Design and The Spirit of the Place, observa que são as coisas mais simples que fazem com que um lugar seja esse lugar, e coloca dois exemplos: o primeiro são as etiquetas das frutas e verduras de um mercado local, que qualifica como expressivas, inventivas e vigorosas, e que sua maneira despretensiosa de ser fala mais das ruas, do que os avisos das grandes lojas. O segundo exemplo consiste nos riquixás em Bangladesh que são decorados por artesãos criativos e habilidosos e dos quais podemos aprender duas grandes lições: a primeira é que sua arte é totalmente espontânea e não se relaciona com motivos comerciais, e a segunda é que não têm patrocínio do governo. $O$ autor assegura que o espírito do lugar se encontra nesses exemplos mais espontâneos e que não é simples para o design descobrir respostas que nos ajudem a invocá-lo, mas que poderia ser algo muito gratificante. 
Por outro lado, do ponto de vista do uso como design, no ano 2005, Jane Fulton Suri, diretora do departamento de Fatores Humanos da IDEO, fez uma compilação de fotografias que mostram maneiras intuitivas de adaptar, explorar e reagir diante de situações em nosso ambiente, prática que chamou de "Intuitive Design" ou Design Intuitivo.

No ano 2006, Uta Brandes e Michael Erlhoff, escrevem o livro Non-intentional Design, um termo criado por eles, que define o "re-design cotidiano do projetado" ou seja, as diferentes funções que podem ser atribuídas a um objeto por seus usuários.

Nesse mesmo ano, é lançado o livro Home-Made Contemporary Russian Folk Artifacts (FIG.3), cujo autor é o artista russo Vladimir Arkhipov e contém fotografias de objetos únicos criados por pessoas comuns e inspirados na falta de acesso a bens fabricados, durante o colapso da União Soviética. Cada fotografia está acompanhada de uma imagem do criador e um texto que relata a história do objeto, porque nasceu, qual é sua função, e os materiais usados para sua criação. No ano 2012, a mesa editorial lança a versão europeia do livro: Home-Made Europe: Contemporary Folk Artifacts, também com fotografias de Arkhipov. Para o jornal The Guardian, de Londres, o autor assinalou: "Se de repente não houvesse mais designers profissionais, ou não ficaram mais produtores de objetos, o processo de criar novos projetos, novas formas, não diminuiria" (MCGUIRK, 2013)
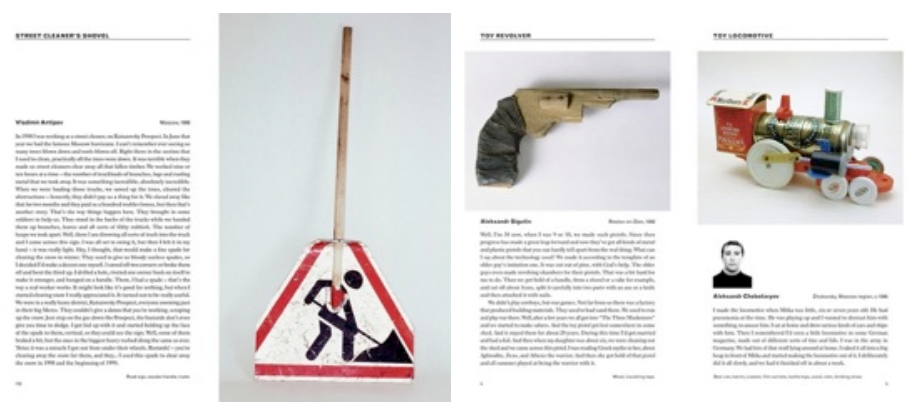

Figura 3 - Páginas do livro: Home-Made Contemporary Russian Folk Artifacts. Fonte: MCGUIRK, 2012

Em março de 2010, a revista virtual de design Core 77, publica um artigo sobre o trabalho do designer estadunidense Gabriel Hargrove acerca das suas séries chamadas Objects of Rural Vernacular, onde recria objetos, costumes e tradições dos ambientes rurais de América do Norte. Um dos exemplos colocados no site da revista é uma armadilha para guaxinins que ajuda a impedir as pragas destes animais, cuja construção é sugerida a partir de um livro chamado American Handy Book for Boys de Daniel Beard, e de elementos que podem se encontrar na cidade, como um reprodutor de VHS antigo. (THE RURAL..., 2010)

Nesse mesmo ano, o designer italiano Daniele Pario Perra, apresenta a primeira parte do livro Low Cost Design, que é resultado de uma pesquisa realizada entre o norte da Europa e o Mediterrâneo sul, onde documenta milhares de exemplos de criatividade espontânea, produzindo um dicionário visual de criações feitas por autores anônimos, que são classificadas em categorias, e que estimulam a reflexão da 
recuperação e o reuso de materiais (FIG.4). A segunda parte do livro foi lançada no ano 2011.

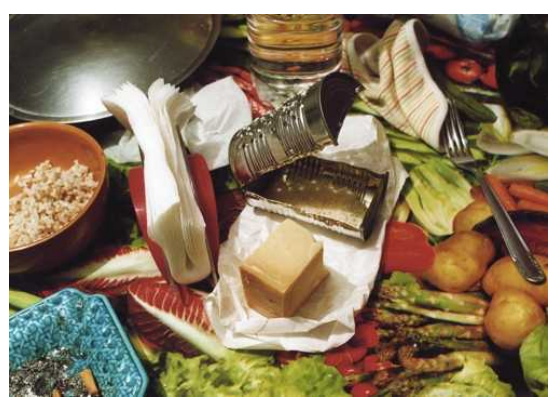

Figura 4 - Ralador de queijo feito a partir de uma lata. Fonte: PERRA, 2010

\section{O DESIGN E A VALORIZAÇÃO DO VERNACULAR OU DE PRÁTICAS REALIZADAS POR NÃO-DESIGNERS.}

Podemos ver o interesse do design pelas práticas realizadas por nãodesigners, seja valorizando o pré-industrial, as coisas feitas à mão, ou registrando os novos usos e formas que ganham, no dia-a-dia, objetos já projetados. No Brasil, a valorização dos artefatos nativos de um lugar pelo design começou em 1958, com a arquiteta italiana Lina Bo Bardi, que viveu no nordeste entre 1958 e 1964, tempo no qual pesquisou sobre cultura material nativa desta região e organizou uma exposição chamada Nordeste em 1963 no Museu de Arte Popular, no Solar do Unhão, em Salvador, mostrando um grande inventário de objetos populares. Ela observa no catálogo da exposição:

Esta exposição procura apresentar uma civilização pensada em todos os detalhes, estudada tecnicamente, desde a iluminação até as colheres de cozinha, as colchas, as roupas, bules, brinquedos, móveis, armas. É a procura desesperada e raivosamente positiva de homens que não querem ser "demitidos", que reclamam seu direito à vida. Uma luta de cada instante para não afundar no desespero, uma afirmação da beleza conseguida com o rigor que somente a presença constante duma realidade pode dar. Matéria-prima: 0 lixo. Lâmpadas queimadas, recortes de tecidos, latas de lubrificantes, caixas velhas e jornais. (LINA, 2009, pág. 116)

Tempos depois, a Escola Superior de Desenho Industrial (ESDI), em 1977, em comemoração a seus quinze anos de existência, promoveu um debate durante o qual Aloísio Magalhães, um dos fundadores da Escola, proferiu uma palestra falando sobre o design industrial nos países do terceiro mundo, onde apontou que a atividade deve abandonar o conceito de forma e função do produto como tarefa prioritária e a visão consumista de produzir só novos bens de consumo, pois neste contexto se transita num espectro amplo de possibilidades, onde estão presentes situações, formas de fazer e usar basicamente primitivas e pré-industriais até tecnologias consideradas de ponta (MAGALHÃES, 1977). Magalhães estava dando espaço a essas formas de fazer pré-industriais que não pertencem ao mainstream. 
Na década de 2000 a 2010, vários pesquisadores centraram seus estudos nestas formas não convencionais de fazer design. Maria Cecilia Loschiavo, no ano de 2000, expõe numa palestra no Politécnico de Milão o que ela chamou de Spontaneous Design, uma prática criativa exercida por moradores de rua que consiste em encontrar soluções aplicáveis a problemas concretos. (SANTOS, 2000)

Depois disso, a pesquisadora Gabriela de Gusmão Pereira, lançou no ano 2002, o livro a Rua dos Inventos, uma coleção de fotografias que começou a realizar desde 1998 acerca das manifestações efêmeras que se criam e se perdem no dia-a-dia nas ruas, objetos ou arranjos de objetos que desenham a realidade de todos os dias dos moradores de rua, de pequenos prestadores de serviços, ou vendedores ambulantes. Pereira (2002) assinala que esses objetos expressam o desenho vernacular brasileiro, pois são uma expressão original do povo e refletem de uma maneira muito própria a realidade da região em que se encontram.

Múltiplos designers nacionais já estudaram o tema a partir de óticas diferentes. Rodrigo Boufleur sob o ponto de vista do reuso de objetos já projetados na criação de novos objetos, no ano de 2006 estudou a gambiarra como uma forma de design vernacular. Em 2007, Adriana Valese pesquisa sobre o Design Vernacular Urbano nas ruas de São Paulo como estratégia de inserção social. E em 2009, Naotake Fukushima analisa o design vernacular da população de baixa renda em Curitiba a partir da sustentabilidade.

De 2010 até agora, podemos citar três projetos: A exposição 'Atlas Ambulantes', gerada a partir do livro do mesmo nome organizado pelos arquitetos Renata Márquez e Wellington Cançado, onde apresentam a experiência de seis vendedores ambulantes de Belo Horizonte, suas cartografias singulares da cidade, itinerários, fotografias tiradas por eles, os equipamentos que utilizam para realizar seu trabalho, uma coleção em escala real de todos os produtos que oferecem, partituras das músicas que utilizam para identificar-se, e uma série de cinco filmes com seus depoimentos. O segundo projeto é o livro Objetos da Floresta (2012) uma recopilação de objetos achados nas comunidades da Amazônia analisados pela designer Andrea Bandoni de Oliveira. (FIG.5)

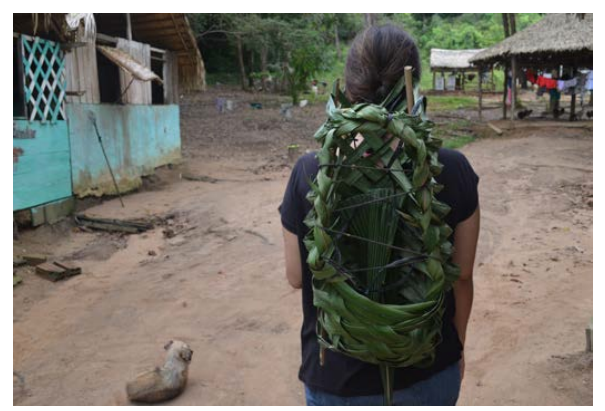

Figura 5 - Panacú. Fonte: BANDONI, 2012, p. 34

E o terceiro é a exposição Design da Periferia (FIG.6), feita pela Secretaria Municipal de Cultura de São Paulo com curadoria de Adélia Borges, que apresenta 
artefatos feitos pelo povo para serem usados na vida cotidiana. Ela assinalou no site da Prefeitura da cidade:

O conceito de periferia é sempre relativo, ele depende de um centro, que pode ser geográfico - um país periférico aos que têm mais voz no mundo, ou a parte de uma cidade que está distante do seu centro, por exemplo - ou pode ser metafórico, no sentido de não pertencer ao mainstream. É com esse sentido que estamos trabalhando. (PREFEITURA, 2013)

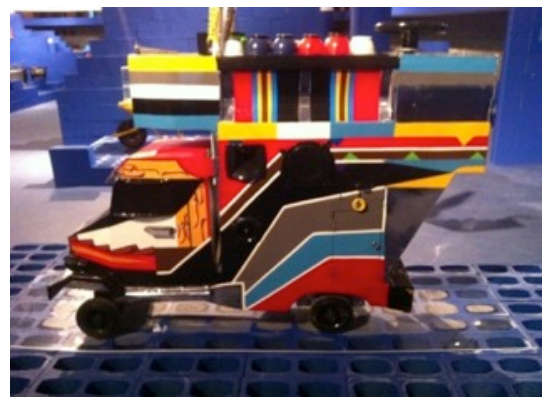

Figura 6 - Carrinho de Vendedores de Café na Bahia - Exposição Design da Periferia. Fonte: Foto de Francesco Mazzarella

\section{CONSIDERAÇÕES FINAIS}

Desde os anos 60's vemos com mais força o interesse do design pelo vernacular ou por práticas realizadas por não-designers. Nos Estados Unidos com a exposição de Rudofsky no MoMa 'Arquitetura sem arquitetos' em 1960 e logo em 1972 com o lançamento do livro do Charles Jencks e Nathan Silver chamado 'Adhocism', onde se retratam formas de fazer ad hoc, usando materiais que estão na mão para resolver problemas reais. No Brasil esta valorização começa na década de $1960 \mathrm{com}$ a pesquisa da Lina Bo Bardi no nordeste, a sua recopilação de objetos populares, fotografias, livros e exposições.

Desta maneira vemos como o design vem se aproximando dessas formas préindustriais de produção, seja valorizando as manifestações vernaculares, ou estudando os novos usos que são dados aos objetos já projetados. Assim, o design valoriza o saber fazer local, resgata tradições, as documenta, conhece outra faceta da cidade, enfim, adquire um grande repertório de oportunidades.

Utilizando estratégias de incorporação de elementos locais e/ou vernaculares nos trabalhos de design, podem-se criar laços mais fortes entre o usuário e o contexto, atingir uma coerência com o círculo cultural onde estão inseridas e fazer um design mais humano, mais aberto à diversidade, menos globalizado.

As oportunidades de ação nesse campo são ilimitadas. O design pode utilizar elementos do dia-a-dia para reafirmar identidades, experimentar novas formas e maneiras de fazer, ir além das propostas do modernismo, fazer uso da sabedoria comum, explorar materiais diferentes, abrir novas possibilidades para o reuso e mostrar estas novas formas a outros países do mundo.

O design pode aprender a partir do mais simples. Neste mundo contemporâneo e hipermoderno nem tudo é high tech. Muitas das suas manifestações continuam 
sendo práticas básicas, que nos lembram que somos seres humanos, e que, por isso mesmo, constituímos uma grande fonte de informações com as quais podemos aprender lições infinitas, de quem o design vem se aproximando cada vez mais nos últimos anos.

\section{REFERÊNCIAS}

BANDONI, Andrea. Objetos da Floresta. São Paulo: Andrea Bandoni de Oliveira. 2012.

BOUFLEUR, R. A questão da gambiarra: Formas Alternativas de Desenvolver Artefatos e sua relação com o Design, 2006, 153 p. São Paulo, Dissertação, Programa de Pós-graduação da Faculdade de Arquitetura e Urbanismo, Universidade de São Paulo, São Paulo, Brasil.

BRANDES, U.; STICH, S.; WENDER, M.; Design by Use. Basel: Birkhäuser. 2009.

BRANDES, U., \& MICHAEL, E. Non Intencional Design. New York: Daad gmhb. 2006

DEAN, D. A slipware dish by Samuel Malkin: An Analysis of Vernacular Design. Em Journal Design History, vol. 7, n³, Londres, 1994.

DÊNIS, R.C. Uma introdução à historia do design. São Paulo: Edgard Blucher. 2000.

FARIAS, P.L. Aprendendo com as ruas: a tipografia e o vernacular. In: Marcos da Costa Braga. (Org. ). O papel social do design gráfico: história, conceitos \& atuação profissional. São Paulo: Senac São Paulo, v. , p. 163-183. 2011.

FUKUSHIMA, N. Dimensão social do design sustentável: contribuições do design vernacular da população de baixa renda. 2009. Dissertação (Mestrado em Design), Universidade Federal de Paraná, Programa de Pós-graduação em Design, Curitiba, Brasil. 2009

FULTON SURI, Jane \& IDEO: Thougthless Acts. Observations on Intuitive Design. San Francisco. 2005.

GARLAND, K. That place, at any rate. Bordeaux: Les Partisans du Moindre Effort, 2004.

GUSMÃO, G. Rua dos Inventos: Desenho Industrial e Responsabilidade social. Perspectivas do ensino de design da pós-graduação, 2001.

HOUAISS, A. Dicionario Houaiss da Lingua Portuguesa. Rio de Janeiro. Ed. Objetiva. 2001

LAMAS, Antônio; MARQUEZ, Renata Moreira.; CANÇADO, Wellington. MUSEU DE ARTES E OFICIOS (BELO HORIZONTE, MG). Atlas ambulante= Walking atlas. Belo Horizonte, Brasil: Instituto Cidades Criativas, 2011

LINA por escrito. Textos escolhidos de Lina Bo Bardi/ organizado por Silvana Rubino e Marina Grinover; Introdução Silvana Rubino. São Paulo: Cosac Naify, 2009.

MAGALHÃES, A. O que o design industrial pode fazer pelo país? In: Revista Arcos, Rio de Janeiro. V.1, 1998, p 8-12. 1977

MCGUIRK, J. Home-Made Europe: the DIY geniuses shaking up design. In: The Guardian/

Disponível

em: 
http://www.guardian.co.uk/artanddesign/2012/may/30/home-made-europe-diydesign-genius. Acesso em: 10 de Fev. de 2013.

PACEY, P. Anyone desinning Anything? Non-professional Designers and the history of Design. In: Jornal of Design History, v.5, n. 3, London. 1992.

PAPANEK, V. Arquitectura e Design. Ecologia e Ética. Lisboa: Edições 70. 1995.

PAPANEK, V. The green imperative: ecology and ethics in Design and Architecture : with 162 illustration, 39 in colour. London: Thames \& Hudson, c1995.

PERRA, Daniele Pario. Low cost design. Milano: Silvana Editoriale, c2010.

PREFEITURA de Sao Paulo (2013) No dia 25 de janeiro, Pavilhão das Culturas Brasileiras inaugura exposição 'Design da Periferia'. Disponible em: http://www.prefeitura.sp.gov.br/cidade/secretarias/cultura/noticias/?p=11907

RICHARDSON, V. Vanguardia y tradición: La reinterpretación de la arquitectura /Vicky Richardson ; tr., Margarita Kirchner. Barcelona, Esp. : Blume, 2001.

RUDOFSKY, B. Architecture without architects. Garden City, New York: Doubleday. 1964

SANTOS, M. Spontaneus Design, Informal Recycling and Everyday Life in Postindustrial Metropolis. Anais do Congresso Politécnico de Milão. Milão . 2000.

SANTOS, Maria Cecilia Loschiavo. Reflexões sobre design e humanismo no mundo contemporâneo. In: CELASCHI, F., DE MORAES, D., Cadernos Avançados em Design: Humanismo; Universidade do Estado de Minas Gerais - Barbacena; EdUEMG, 2013.

THE RURAL Design Vernacular: Objects that Expose Agency, by Gabriel Hargrove. Core $77 . \quad$ Disponivel em: http://www.core77.com/blog/featured_items/the_rural_design_vernacular_objects_t hat_expose_agency_by_gabriel_hargrove_16880.asp. Acesso em: 8 Maio 2013.

VALESE, A. Design vernacular urbano: a produção de artefatos populares em São Paulo como estratégia de comunicação e inserção social. 2007. 107f. Dissertação (Programa de Pós-graduação em Design e semiótica), São Paulo, Brasil 